STRUCTURAL BIOLOGY COMMUNICATIONS

ISSN 2053-230X

Keywords: IYCr; macromolecular crystallization

\section{The state-of-the art in macromolecular crystallization: the IYCr series concludes}

\author{
M. S. Weiss, ${ }^{a *}$ W. N. Hunter ${ }^{\text {b* }}$ and H. M. Einspahr ${ }^{\mathrm{c} *}$
}

${ }^{\text {a}}$ Helmholtz-Zentrum Berlin für Materialien und Energie, Macromolecular Crystallography (HZB-MX), Albert-EinsteinStrasse 15, D-12489 Berlin, Germany, 'bivision of Biological Chemistry and Drug Discovery, College of Life Sciences, University of Dundee, Dundee DD1 5EH, Scotland, and ${ }^{\mathrm{C}}$ PO Box 6483, Lawrenceville, NJ 08648-0483,USA.

*Correspondence e-mail: manfred.weiss@helmholtz-berlin.de,w.n.hunter@dundee.ac.uk, hmeinspahr@yahoo.com

When 2014 was announced as the International Year of Crystallography (IYCr) we, as editors, wondered how Acta $F$ could commemorate this event. Very quickly we decided to commission a set of articles on the state-of-the-art in the many different aspects of macromolecular crystallization. We decided to publish an article in each of the 2014 issues and to conclude the year by combining all the articles into what would be the definitive book of macromolecular crystallization. What we did not anticipate, however, was the overwhelming response of our prospective authors. There were so many interesting areas that authors were willing to cover that we ended up publishing almost twice as many of these articles. Therefore, the IYCr series is only now coming to a conclusion and it is this that we celebrate on this month's cover.

The series has been an outstanding success with a total of 20 articles, and it will end with the publication of the final two articles early in 2016. Many of the papers in the series are already among the most downloaded and cited in our journal. Once we have published the final articles, the complete collection will become available to readers as a virtual issue online, and in other formats on demand. Further details will be provided soon, so watch this space!

The cover this month is a composite of illustrations that have appeared in IYCr articles over the last two years. We thank the authors of all the contributions to this series for their support of the project. We also especially thank Professors Alex McPherson, Juan Manuel Garcia-Ruiz and Bernhard Rupp for their advice and guidance as the series evolved.

It is ten years since Acta Cryst. F first devoted its cover illustration to images of crystals. In this time the journal has moved from an almost purely crystallization journal to a fullfledged structural biology journal. It now publishes structural biology research involving a range of structural biology techniques including crystallography, NMR, cryoEM and others, and we look forward to developing the journal further.
Acta Crystallographica Section F STRUCTURAL BIOLOGY COMMUNICATIONS

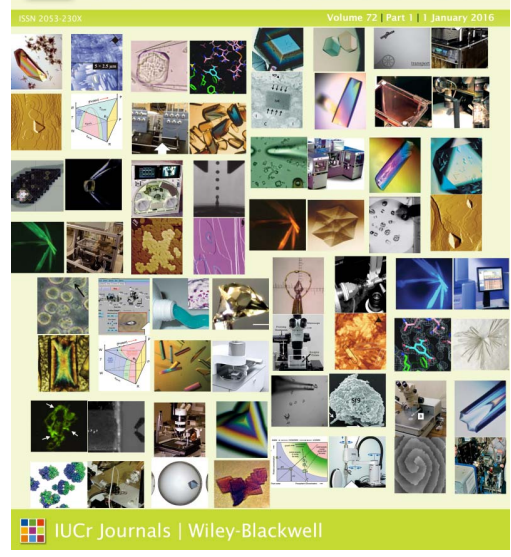

(C) 2016 International Union of Crystallography 